\title{
FOTOGRAFIA E ARQUIVO, ENTRE O TANGÍVEL E O INTANGÍVEL
}

\author{
Rafael Franklin Almeida Bezzon ${ }^{1}$
}

\section{Antecedentes}

Este artigo é fruto de pesquisa realizada junto ao Arquivo Miyasaka, localizado na cidade de Ribeirão Preto, São Paulo, que resultou em uma dissertação de mestrado junto ao Programa de Pós-Graduação em Ciências Sociais da Universidade Estadual Paulista (UNESP), Faculdade de Ciências e Letras, Campus Araraquara. ${ }^{2}$ Proponho a partir desse texto refletir sobre o fazer antropológico e sua relação com imagens, e dessa forma trabalhar teórica e metodologicamente uma outra forma de relacionar imagens e a experiência de pesquisa etnográfica. ${ }^{3}$ Para isso selecionei, organizei e montei alguns painéis ${ }^{4}$ fotográficos com o intuito de construir uma reflexão, através das fotografias, sobre a experiência com o arquivo e tudo que o envolve, ou seja, as imagens - fotos, lembranças, narrativas memorialísticas, entre outras - e as principais interlocutoras, D. Tereza - viúva do fotógrafo, e Elza - filha do fotógrafo.

$\mathrm{Na}$ história da fotografia, as máquinas e o ato de registrar e produzir imagens permitiram diferentes encontros entre a câmera e os objetos fotografados. Fruto desses encontros foram produzidas uma grande quantidade de artefatos fotográficos, daguerreótipos, fotografias, negativos fotográficos, provas de contato, polaroides, entre outros materiais típicos desse processo.

Um dos campos do conhecimento que se beneficiou e se relacionou com a fotografia e seus produtos foi a antropologia. Segundo a antropóloga e historiadora da

\footnotetext{
${ }^{1}$ Universidade Estadual Paulista, Brasil. Email: rafaelbezzon@gmail.com ORCID id: https://orcid.org/0000-0002-5337-9072

2 A dissertação é intitulada "O Japonês da Gravata Borboleta - Trajetória, Arquivo e Imagem: a experiência de pesquisa no e com o Arquivo Miyasaka".

${ }^{3}$ Já é amplamente conhecido, através da bibliografia tangenciando os estudos antropológicos envolvendo imagens e diferentes formas de refletir, teórico e metodologicamente, sobre seu uso nas pesquisas. No caso deste texto, a outra forma a que me refiro, se trata da forma desenvolvida por mim em diálogo com o contexto de pesquisa em que estava inserido.

${ }^{4}$ Neste texto apresentarei quatro painéis.
} 
antropologia Elizabeth Edwards, a fotografia é listada como um instrumento/ferramenta metodológica desde a primeira edição do manual (1874), produzido pelo Instituto Antropológico da Universidade de Cambridge em conjunto com a Associação Britânica para o Avanço da Ciência, intitulado: "Notes and Queries on Anthropology - N\&Q" (Edwards, 2016: 280).

A relação de vizinhança e amizade que permeia a fotografia e a antropologia se estabelece desde os primeiros usos da câmera com o objetivo de registrar diferentes corpos e formas humanas, por meio da fotografia antropométrica (Edwards, 2016: 278). A durante as duas últimas décadas do século XIX, a produção de fotografias passa por uma grande transformação e popularização com a invenção no ano de 1888 da máquina Kodak "caixão", uma das primeiras câmeras portáteis com uma campanha publicitária que marcou a história: "You press the button, we do the rest" ("Você aperta o botão, nós fazemos o resto").

Dez anos após o lançamento da primeira câmera de rolo, ocorre uma das principais expedições de interesses antropológicos da história, comandada por W.H.R. Rivers, C.G. Seligman e A. C Haddon, esse último, adepto e praticante da fotografia, conhecida por "The Cambridge Anthropological Expedition to Torres Strait". Essa expedição, que já foi amplamente estudada, foi importante entre outras coisas por produzir um extenso material imagético produzido em campo, sejam fotografias ou mesmo imagens em movimento. ${ }^{5}$

Desde então, a fotografia e a antropologia se encontraram e constituíram alianças para o registro e a produção de conhecimento em diferentes momentos durante o século XX. Em um de seus usos mais conhecidos, na famosa e sempre lembrada, monografia clássica de Bronislaw Malinowski, Os Argonautas do Pacífico Ocidental (1922); já em outro período, através da produção clássica, histórica e monumental de Gregory Bateson e Margareth Mead The Balinese Character (1942); e em um período mais recente (1980), através de uma grande renovação no interesse sobre as fotografias e os arquivos que habitam, sejam eles de antropólogos ou fotógrafos que documentaram diferentes períodos da sociedade e seus acontecimentos.

\footnotetext{
5 Através desse link: https://aso.gov.au/titles/historical/torres-strait-islanders/ é possível assistir a pequenos trechos de filmagens realizadas por A.C. Haddon.
} 
Os arquivos produzidos e gerados por importantes pesquisadores, destacados homens públicos, fotógrafos profissionais e amadores se espalham pelas cidades, muitas vezes recheados de fotografias guardadas em pequenas caixas, gavetas e armários. Meu encontro com a fotografia e a antropologia se passa com um arquivo fotográfico, este se encaixa em um entendimento amplo “[...] como um conceito que se refere a todo e qualquer conjunto ou coleção de fotografias de determinado período histórico, armazenadas conjuntamente com alguma intenção, mesmo que apenas para guardar. [...]" (Banks; Vokes, 2010: 338).

Tony Miyasaka foi um importante fotógrafo, laboratorista, comerciante e professor de fotografia, atuou principalmente na cidade de Ribeirão Preto, São Paulo. Durante sua trajetória de vida foi mais reconhecido pelo seu trabalho como comerciante, suas fotos ficaram esquecidas e adormecidas seu sono arquivístico até o ano de sua morte, 2004.

Sua atuação foi múltipla tendo trabalhado em praticamente todas as etapas de produção da fotografia, iniciou sua trajetória retocando retratos junto de seu irmão mais velho Kazuo. Após um período nessa função, não se mostrando muito talentoso com o pincel e a tinta, assumiu a função de fotógrafo retratista para o estúdio da família. $\mathrm{O}$ fotógrafo não se limitou aos trabalhos realizados dentro do estúdio, prestou serviços fotográficos para diferentes órgãos governamentais, registrando os eventos culturais, políticos e sociais vinculados à prefeitura, além de prestar serviços fotográficos para a perícia da polícia. Atuou como foto repórter para jornais da cidade, A Cidade e Diário de Notícias, e para jornais de ampla circulação como Folha de São Paulo e Gazeta Esportiva.

O fotógrafo sempre esteve envolvido com os diferentes movimentos artísticoculturais atuantes na cidade, tendo participado ativamente junto ao Cine Foto Clube de Ribeirão Preto, popularmente conhecido como Cinefoto, atuando por um período em sua diretoria e participando ativamente das atividades do clube entre elas os salões e concursos fotográficos espalhados pelo país. Junto de Rubens Francisco Lucchetti, Bassano Vacarini, Waldemar Fantini e Milton Rodrigues, fundou e participou ativamente das atividades e produções realizadas junto ao Centro Experimental de 
Cinema - C.E.C. ${ }^{6}$, que produzia filmes experimentais e animações feitas diretamente nos negativos fílmicos, entre outras técnicas.

O Arquivo Miyasaka é segmentado em três grandes conjuntos de fotografias e negativos: "Jovem Miyasaka", compreende o período das décadas de 1950 e 1960 quando trabalhou como fotógrafo profissional e iniciou seu projeto pessoal de documentação das transformações da cidade e suas gentes; "Fotos Aéreas", uma das paixões do fotógrafo; e "Fotos Artísticas", correspondendo à sua produção feita próximo ao fim da vida. Há mais um corpus constituindo o conjunto "Jovem Miyasaka", são os "Negativos Doentes" armazenados em um espaço diferente devido à condição de deterioração dos negativos.

Como me contou Elza - filha do fotógrafo e uma das principais interlocutoras durante a pesquisa -, a separação do arquivo em três corpus de fotografias e negativos havia sido sistematizada pelo próprio fotógrafo, somente o conjunto separado (Negativos Doentes) após a morte do fotógrafo não tomou forma através de suas mãos e olhos. Em uma de minhas idas ao arquivo, em uma conversa com Elza, ela se se referiu à produção fotográfica que é objeto desta pesquisa como sendo da juventude do fotógrafo, foi então que juntos resolvemos utilizar as alcunhas empregadas para se referir aos conjuntos que compõem o arquivo.

O conjunto "Jovem Miyasaka" passou por uma espécie de auto curadoria por parte do próprio Miyasaka entre os anos de 2002 e 2004, como contou Elza. Nos dois anos que antecederam sua morte, Miyasaka levou para sua casa os acervos de negativos - "Jovem Miyasaka", "Foto Aéreas" e "Fotos Artísticas" - guardados em uma de suas lojas que à época estava encerrando suas atividades. É desse modo que o fotógrafo inicia o processo de seleção dos negativos a serem guardados, enquanto os outros eram descartados em um saco de lixo preto. Ao mesmo tempo, é como se o fotógrafo realizasse um processo de auto arquivamento ao selecionar o que deveria ser ou não guardado, definindo o primeiro ordenamento de seu acervo e uma primeira memória sobre sua obra fotográfica.

O corpus "Jovem Miyasaka" é de grande importância como documento social da cidade de Ribeirão Preto durante o período dos anos de 1950 e 1960. Devido ao seu

\footnotetext{
${ }^{6}$ O Centro Experimental de Cinema esteve em funcionamento do ano de 1960 até o ano de 1965, tendo produzido mais de 14 filmes, com participações em festivais no Brasil e na Europa.
} 
trabalho como fotógrafo retratista de estúdio, em seus retratos aparecem as grandes personalidades políticas, empresariais, acadêmicas e religiosas que compunham a elite da sociedade ribeirão-pretana. Os assuntos giram em torno de seus prédios, ruas e avenidas, o processo de verticalização, as obras e seus canteiros.

Sua objetiva também registra alguns símbolos das transformações por qual passava a cidade, como a chegada das grandes empresas multinacionais, os luminosos de néon nas fachadas dos prédios, os espaços de consumo, vitrines de lojas, postos de gasolina, escolas, a chegada da Universidade de São Paulo - USP, e a construção de seu campus. Nesse conjunto já é notável muitas fotografias aéreas uma das paixões do fotógrafo. Como contou D. Tereza, Miyasaka aos finais de semana tinha por hábito alugar por algumas horas um avião ou mesmo um helicóptero com o objetivo de fotografar a cidade, seus bairros e prédios.

III

[...] Os elementos de um contexto convencionalmente reconhecido parecem se pertencer mutuamente assim como elefantes, lonas, palhaços e acrobatas pertencem a um circo. [...] (Wagner, 2012: 112).

Como nos lembra Roy Wagner no excerto acima, alguns contextos são reconhecidos pela familiaridade como os elementos que o compõem se associam e se comunicam, a metáfora com o circo é um bom exemplar de um contexto bem definido. As pesquisas antropológicas que envolvem a etnografia, sempre prescindem de uma partida, viajar a outros espaços, é uma característica marcante da antropologia. As viagens podem ser realizadas em diferentes escalas, das grandes distâncias, como nas monografias clássicas da antropologia que ocorrem em regiões longínquas da Oceania, África e América do Sul. E viagens que se passam em escalas menores, nas pequenas distâncias percorridas durantes as jornadas que fazemos ao sair de nossa própria casa e nos deslocamos a outro lugar dentro da cidade, do bairro ou mesmo na própria rua.

Para Michel Agier (2015: 19), "Não existe etnólogo sem uma partida, sem sair de casa e ir olhar o mundo, que começa bem perto, além do círculo privado, da casa, dos sentimentos familiares, amorosos, fraternais. Tomar uma distância daquilo que compõe o seu 'eu' é o primeiro passo. [...]". Sair de casa e se propor a olhar de uma forma 
diferente, inquiridora, para as situações cotidianas, já se torna uma pequena partida para uma experiência antropológica. Cada partida realizada em diferentes escalas, os elementos encontrados, as relações estabelecidas e suas possíveis associações conformam o contexto em que se insere a experiência de pesquisa.

Os contextos são criados pelo pesquisador como um constructo com o objetivo de dar sentido, significado pra as experiências e associações que realizamos ao nos depararmos com diferentes formas simbólicas (narrativas, objetos, imagens etc.). Como bem define Roy Wagner, "Um contexto é uma parte da experiência - e também algo que nossa experiência constrói; é um ambiente no interior do qual elementos simbólicos se relacionam entre si e é formado pelo ato de relacioná-los. [...]" (Wagner, 2012: 111112). Assim, construímos através do estabelecimento de relações ente diferentes elementos os contextos empíricos de nossas pesquisas, o que os antropólogos convencionalizaram em enunciar como o trabalho de campo

Assim como as viagens podem se diferenciar pelas escalas em que são realizadas, o antropólogo americano também aponta para a existência de uma variedade, quantidade e extensão de contextos que podem existir em determinada cultura. Sendo que muitas vezes um contexto é composto por uma miríade de outros pequenos contextos que se articulam, como lembra o antropólogo americano "Alguns [contextos], de tão tradicionais, parecem quase permanentes e imutáveis, ao passo que novos contextos são criados o tempo todo na produção de afirmações e situações em que consiste a vida cotidiana.” (Wagner, 2012: 112).

Se há contextos onde os elementos se pertencem de uma maneira natural, como o circo citado por Roy Wagner, há outros que se constroem através de outros elementos como o arquivo, as fotografias, pessoas e possíveis associações de relações que se se estabelecem entre eles. Procurar explicitar como se deram essas relações se mostra um caminho interessante para compreendermos o contexto de realização da pesquisa e seu significado.

A experiência de pesquisa junto ao Arquivo Miyasaka se organizou através de uma etnografia no e com arquivo, de seu espaço e a lógica que o orienta, com as imagens e pessoas envolvidas e que estabelecem uma relação com o arquivo, as fotografias e o fotógrafo. 
A postura perante as fotos, devido às circunstâncias da pesquisa, era de se comprometer com o afeto uma espécie de força que emanava e estabelecia uma relação com o observador. Afinal, assim como Roland Barthes, “[...] me interessava pela Fotografia por "sentimento"; eu queria aprofundá-la, não como uma questão, um tema, mas como uma ferida: vejo, sinto, portanto, olho e penso. (Barthes 2011: 31)”.

Uma das potencialidades do tratamento etnográfico para um arquivo é a possibilidade de relação com interlocutores que estabelecem um vínculo íntimo com as imagens, como bem observa a antropóloga carioca Olivia Maria da Cunha (2005: 10). Segundo a autora, "sair do arquivo", buscar relações permeando o artefato imagético e as pessoas que com ele se relacionam, ver fotos com a(o)s interlocutora(e)s e realizar entrevistas mediadas por imagens, se tornam procedimentos interessantes para a construção do conhecimento antropológico.

Assumindo essa postura e perspectiva teórico-metodológica, tudo se passou como se o Arquivo Miyasaka, sua lógica de orientação e os espaços que o compõe, junto às fotografias, textos, objetos e às pessoas que se relacionavam com o fotógrafo, $\mathrm{o}$ arquivo e as fotografias, se constitui como o campo da pesquisa. Conforme as pastas analógicas e digitais eram abertas as fotografias ali guardadas eram animadas, iluminadas e elas, por sua vez, também animavam e iluminavam o observador, despertando a imaginação e a memória através do afeto estabelecido com a imagem.

A antropologia de uma maneira geral, de acordo com Favret-Saada (2005, p.155), sempre desconsiderou, ignorou ou negou o afeto nas experiências de campo. Uma das potencialidades do afeto como categoria analítica no trabalho antropológico é a capacidade de, nas palavras da autora, “[...] apreender uma dimensão central do trabalho de campo (a modalidade de ser afetado); [...]” (Fravet-Saada, 2005, p. 155). Nesses momentos as fotografias (os objetos), geram afetos que produzem o que Marilyn Strathern chama de "efeitos de deslumbramento" no observador que olha e se relaciona com determinada imagem, e no pesquisador ao ser afetado pelas narrativas evocadas.

Strathern, retoma uma concepção de Alfred Gell para analisar a agência de objetos em contexto etnográfico, nas palavras da autora: “[...] O agente faz os eventos acontecerem. A arte, segundo ele, pode ser o ator ou pode sofrer a ação, ser agente ou paciente, num campo de agentes e pacientes que assumem formas diversas e têm efeitos diversos uns sobre os outros. [...] (Strathern 2014: 362)". As fotos, assim como as 
pessoas, também podem ser entendidas como interlocutoras, e foi dessa maneira que com elas me relacionei.

Como nos lembra Elizabeth Edwards, as fotos “[...] são locais privilegiados para as interações sociais ocorridas em campo. Elas facilitam o trabalho de campo permitindo atos de amizade, troca e diplomacia, além de auxiliarem no estabelecimento de uma comunicação compartilhada [...] (Edwards 2015: 242-243)".7 Assim, as fotos podem ser entendidas como espaços privilegiados onde ocorrem encontros e se formam relações envolvendo o pesquisador, as pessoas e outras imagens. Foi com elas e por meio delas que muitas relações se formaram, afinal são objetos imagéticos imóveis congelam determinado acontecimento da vida na forma de imagem, quando entram em contato com o olhar do observador são animadas e animam a memória, as lembranças, a subjetividade de quem a olha e assim permitem que novas relações se formem.

Dessa forma, penso que os "Encontros Fotográficos", podem ser entendidos como um momento da experiência de pesquisa em que os diferentes observadores se permitem a serem afetados tanto pelas fotografias como pelas outras imagens memórias, lembranças e histórias - evocadas pelos interlocutores.

São esses eventos de grande significância vividos durante a experiência de campo, que a imagem, através do olhar do observador, pelo contato com seu corpo, age acionando, engatilhando, provocando a evocação - expressão - de memórias, lembranças e histórias, produzindo narrativas através daquelas fotos.

Proponho, portanto, analisar as imagens não apenas pensando em seus conteúdos semióticos, essenciais para que sejam entendidas em seu contexto de produção e leitura, mas pensá-las por meio dos efeitos e afetos produzidos e vivenciados durante o contato com as fotos, através de sua significância como espaço de interações sociais, momentos que intitulo de "encontros fotográficos".

IV

[...] Se existe um visível escondido debaixo de um invisível, não é o arco voltaico que o revelará, que o libertará do não ser, mas a encenação das palavras, o momento de diálogo entre a voz que as faz ecoar e o silêncio das imagens que mostram a ausência daquilo que as palavras dizem. (Rancière, 2018: 42)

\footnotetext{
${ }^{7}$ Todas as traduções são de minha autoria.
} 
A seleção realizada durante a pesquisa é composta de 300 imagens de um universo de aproximadamente três mil fotografias. Foram selecionadas e apresentadas na dissertação quarenta e uma fotos, além de seis painéis. Desse conjunto, foram impressas cento e vinte imagens de onde saíram a seleção final para montar os painéis.

Durante a escolha desse conjunto, a intenção foi partir de imagens que tiveram uma grande significância durante a realização da pesquisa, aquelas que agiram produzindo novas relações entre os observadores e as outras imagens. Os acontecimentos significativos, que são cheios de significância para o andamento da pesquisa são da ordem da sensação, nas palavras de Deleuze (2007: 42)

\footnotetext{
“[...] A sensação é o contrário do fácil e do lugar-comum, do clichê, mas também do 'sensacional', do espontâneo etc. A sensação tem um lado voltado para o sujeito (...) e um lado voltado para o objeto ('o fato', o lugar, o acontecimento). Ou melhor, ela não possui lados; ela é as duas coisas indissoluvelmente, é ser-no-mundo, como dizem os Fenomenólogos: ao mesmo tempo eu me torno na sensação e alguma coisa acontece pela sensação, um pelo outro, um no outro. [...]".
}

As fotos, o desenho, a gravura, a pintura, as imagens de uma maneira geral também possibilitam ativar criativamente a atuação da imaginação e da subjetividade do observador. Quando entram em contato com o nosso corpo, através do olhar ao olhá-la, com o tato ao manuseá-la, pela audição ao narrar, as imagens, especialmente as fotografias, realizam uma espécie de performance. Nas palavras de Elizabeth Edwards (2001: 18), as [...] Fotografias tem uma qualidade performática, um tom afetivo, uma relação com o observador, uma fenomenologia não apenas do conteúdo, mas como objetos sociais ativos projetando e se movendo entre outros tempos e espaços. [...]”.

O Arquivo Miyasaka está localizado na antiga residência do fotógrafo, e atual morada de sua filha e sua viúva, Elza e D. Tereza. É uma casa-arquivo. Certa vez, quando via algumas imagens, sentado na mesa que utilizava para as pesquisas, elas estavam sem identificação ou informação alguma. Eram em sua maioria retratos produzidos em estúdio, grande parte estava em negativo fílmico e havia algumas fotografias. 


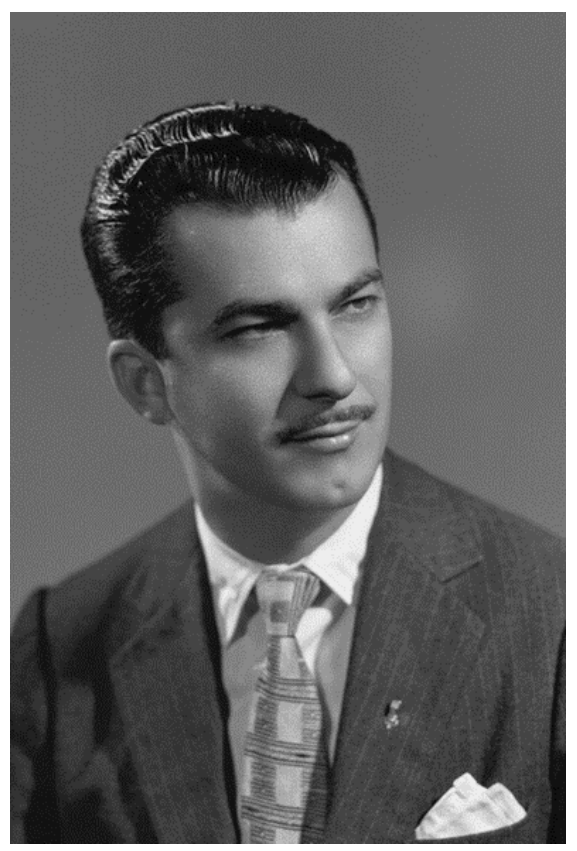

Figura 1 - Fotografia de autoria de Tony Miyasaka, realizada na década de 1950, sem uma data específica. Na foto está Jovino Campos, atuou como jornalista, e vereador suplente na cidade de Ribeirão Preto entre os anos de 1956 e 1963.

Após um período olhando para os retratos, pegando os negativos e os colocando sobre uma luminária de mesa, que utiliza uma luz de led branca, meu olhar havia sido capturado, atacado, pelas diferentes poses dos retratados, e principalmente pelas iluminações propostas pelo fotógrafo na construção dos retratos. Foi então - quando menos se espera - que D. Tereza apareceu na porta da sala onde pesquisava. Ela ficou por ali, recostada ao batente da porta, me observando por um tempo. Lembro, ao vê-la de relance, da expressão de curiosidade no rosto.

Após alguns minutos ela se aproxima da mesa em que estavam espalhados os negativos. Observa, por um tempo, os negativos: o abrir e fechar dos envelopes onde são individualmente armazenados, os gestos comedidos durante o manuseio ao colocálos na contraluz, e a guarda deles nos invólucros feitos de papel $\mathrm{pH}$ neutro. Já havia algum tempo que eu estava imerso em uma imagem, olhava para ela e pensava em como aquele rosto era familiar. Passados uns minutos, D. Tereza pega algumas fotografias e começa a olhá-las. Ela se volta para a foto ${ }^{8}$ que estava em minhas mãos, ao vê-la ela inicia de forma bastante despretensiosa uma conversa sobre aquele retrato. Aos poucos foram surgindo as primeiras informações: seu nome, atuação profissional e política, e as

\footnotetext{
${ }^{8}$ A foto em questão é a figura 1.
} 
lembranças envolvendo o fotografado e minha interlocutora. Aquele rosto sem história e sem nome, aos poucos, foi ganhando vida.

Esse encontro fotográfico me afetou, e despertou meu olhar para os retratos e os rostos capturados pelo fotógrafo. Os efeitos desse acontecimento para o desenrolar da pesquisa se deram de diferentes formas, os retratos que em um primeiro momento pareciam todos iguais começaram a se mostrar em seus detalhes, por outro lado em suas fotografias realizadas em contextos sociais, políticos e culturais, rostos começaram a se mostrar pregnantes, capturavam minha atenção. Permitindo o estabelecimento de uma das linhas de leitura e relação com as imagens e o arquivo, e que se expressam nos painéis por mim montados.

É o que se passa quando em um dos encontros que tive com Elza vimos uma fotografia de um prédio inacabado e com o desenrolar da pesquisa foi possível identificar uma série de fotografias, em escala temporal, sobre a construção desse edifício. Ao entra em contato com a imagem, Elza começou a rememorar um hábito de seu pai, o fotógrafo. Ele gostava de sair pelas ruas da cidade, principalmente a região central, fotografando e documentando a construção de diferentes prédios, entre outros assuntos que passaram pelas lentes de sua câmera. Enquanto víamos a foto, Elza me falou algo que reverberou em mim e na pesquisa: "Meu pai era meio arquiteto, ele estava sempre olhando para os prédios".

Foi então, que comecei a olhar para esses prédios capturados pelo fotógrafo em seus diferentes momentos. Esses esqueletos-urbanos estão sempre presentes, intencionalmente ou não, compondo a paisagem urbana. Foi durante esse encontro fotográfico, a princípio sem muita importância, que permitiu o estabelecimento de uma outra linha de leitura e relação, e posteriormente a montagem de um dos painéis que apresento neste texto: a figura 4 - "Painel II". 


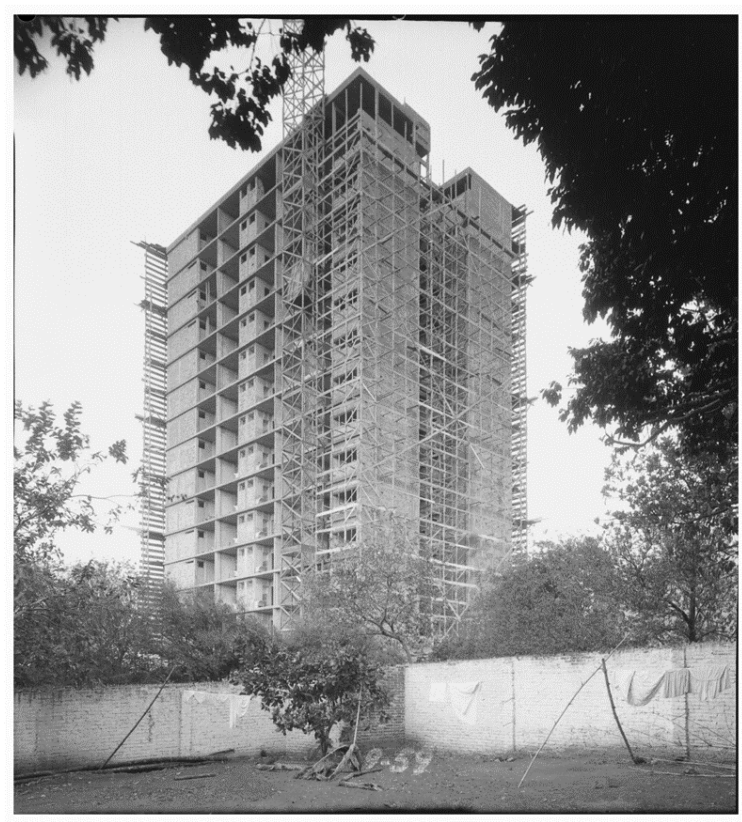

Figura 2 - Prédio em construção na cidade de Ribeirão Preto, região central. Autor da fotografia: Tony Miyasaka, provavelmente no ano de 1959. A imagem foi digitalizada direto do negativo e positivada através do Photoshop. (Fonte: Acervo de Fotografia e Negativos de Tony Miyasaka - Arquivo Miyasaka).

[...] Sem chegar a ser um sujeito, a imagem é muito mais que um objeto: ela é o lugar de um processo vivo, ela participa de um sistema de pensamento. A imagem é pensante. (Samain 2012: 158).

Assim, as fotografias permitem ao observador aceder à possibilidade de, através de sua própria leitura da imagem e das informações que a envolvem, criar ficções em torno de suas tramas (Kossoy 2009: 48). Desse modo, ao refletir durante o segundo campo (da escrita) sobre esses "encontros fotográficos" me pareceu interessante recriar esses momentos através das imagens, portanto ao montar os painéis no formato proposto parto da perspectiva de que as imagens têm a potência e a qualidade de terem uma vida própria.

Didi-Huberman (2012: 209), aponta que a imagem estendeu tanto seu território de ação que nos dias de hoje é difícil pensar sem orientar-se através de imagens. Dessa maneira, é como se elas estivessem onipresentes na construção de reflexões acerca dos acontecimentos do mundo, assim pensar através e com as imagens se torna uma 
experiência interessante, afinal como nos ensinou Samain (2012: 158) a imagem é pensante.

Portanto, proponho aqui realizar, com base em um conjunto de imagens selecionadas durante o processo de imersão com o arquivo, as fotografias e os interlocutores e junto das reflexões e análises produzidas durante o segundo campo, uma "experiência de pensamento" com e através das fotografias. Para refletir e tentar recriar os efeitos e afetos compartilhados durante a pesquisa a partir das próprias imagens fotográficas, afinal elas pensam, fazem pensar, agem, iluminam e animam seus observadores.

O experimento que realizei se baseia em uma seleção de imagens, a partir da desmontagem dessas fotografias de seus lugares de exibição e guarda no Arquivo Miyasaka, para uma (re)montagem, um novo ordenamento de visualização, e leitura proposto por mim e inspirado nos painéis produzidos por Aby Warburg (1866-1929).

As pranchas criadas por Warburg eram montados em um pano preto, se configurando como grandes negativos que constituem novas imagens. Ou seja, os painéis são montados procurando seguir uma relação de vizinhança entre as imagens selecionadas. Dessa forma, os painéis permitem e, ao mesmo tempo, propõem ao observador realizar "[...] uma viagem, melhor dizendo, viagens. (Samain 2011: 39)", deslocamentos e percursos com, e através das imagens selecionadas e ali montadas que procuram expressar as interlocuções e relações entre elas.

O conjunto de fotografias selecionadas e (re)montadas compondo os painéis por mim criados, procuram demonstrar a multiplicidade temática: fotos em contextos sociais e políticos, fotografias aéreas e de registro de pessoas; o experimentalismo na busca por novos ângulos, temas e formatos; e a trajetória do fotógrafo ribeirão-pretano penso figura 3 - com fotos que tematizam diferentes momentos da vida do fotógrafo: sua chegada no campo, sua ida para a cidade, seus primeiros contatos com a fotografia, e sua atuação profissional.

Esses painéis foram montados tendo por objetivo expressar, através das imagens, a relação estabelecida através dos afetos e efeitos experienciados durante os "encontros fotográficos", e que foram centrais para o estabelecimento de linhas de leitura e relação com o arquivo e suas imagens. Os painéis têm por objetivo permitir ao observador 
realizar essas viagens a que Etienne Samain se refere, possibilitando a construção de diferentes leituras para as montagens.

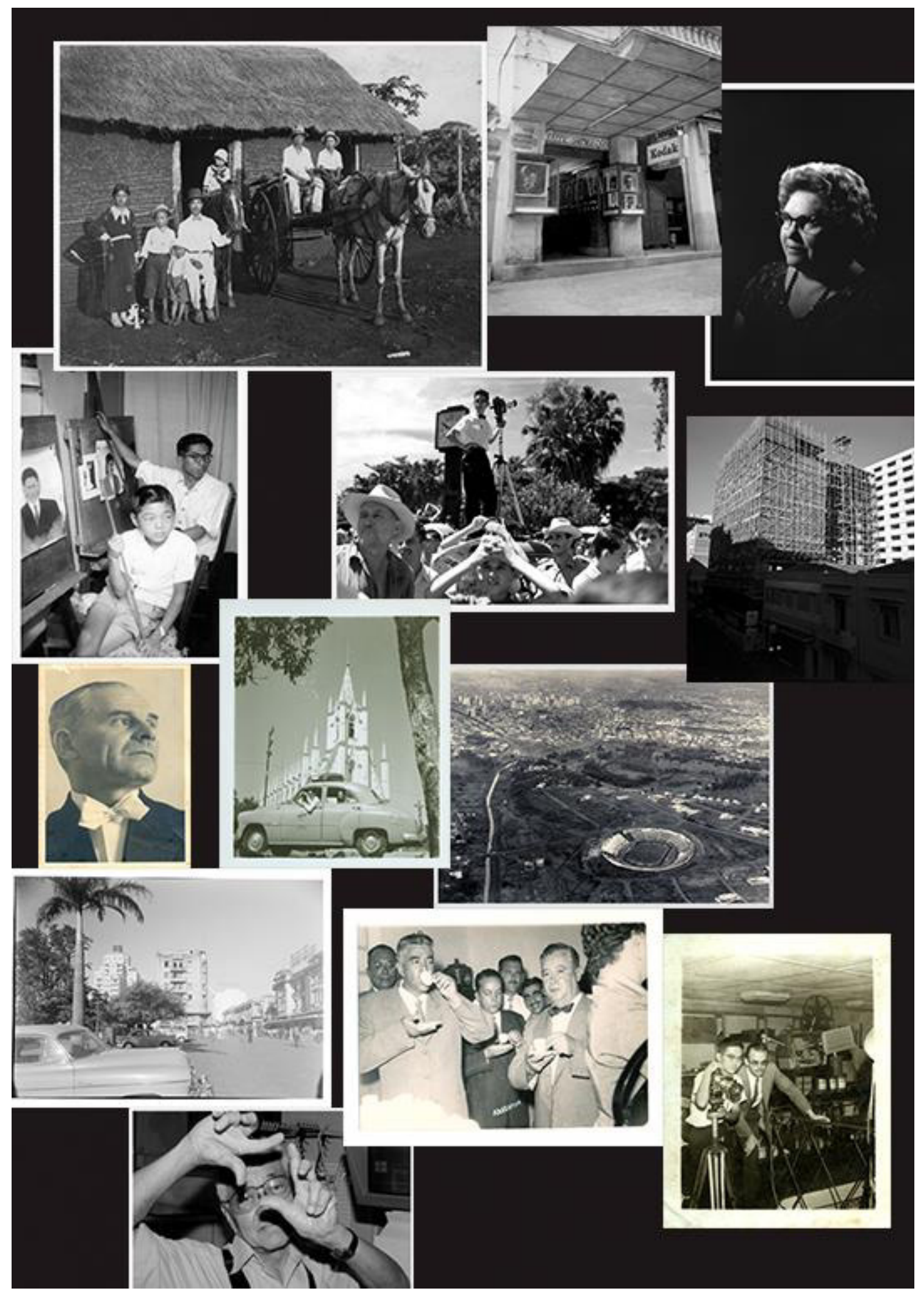

Figura 3 - Painel I, Trajetória. Autor: Rafael F. A. Bezzon. Fonte: Arquivo Miyasaka e Arquivo Público e Histórico de Ribeirão Preto. 


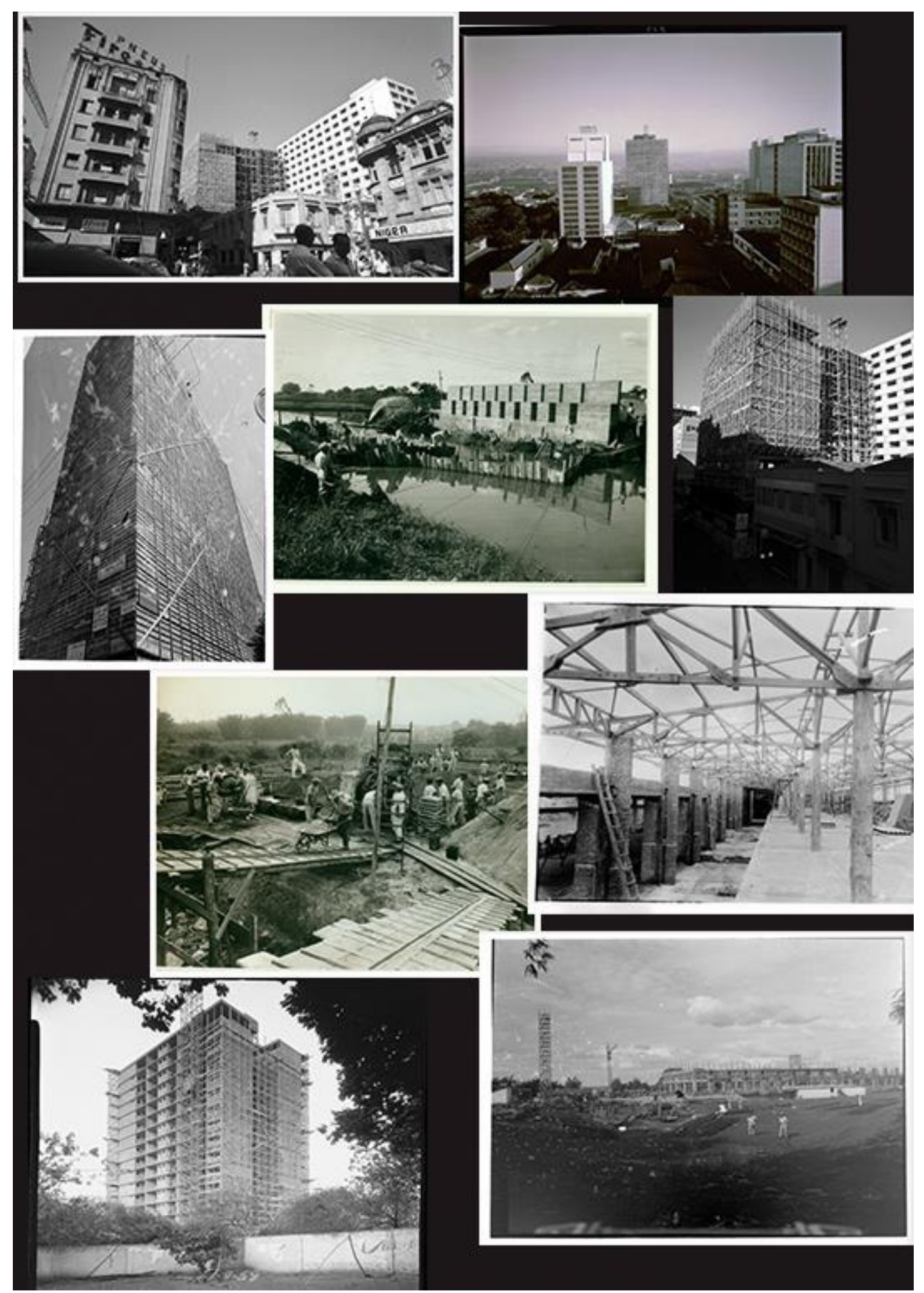

Figura 4 - Painel II, Esqueletos Urbanos. Autor: Rafael F. A. Bezzon. Fonte: Arquivo Miyasaka e Arquivo Público e Histórico de Ribeirão Preto. 


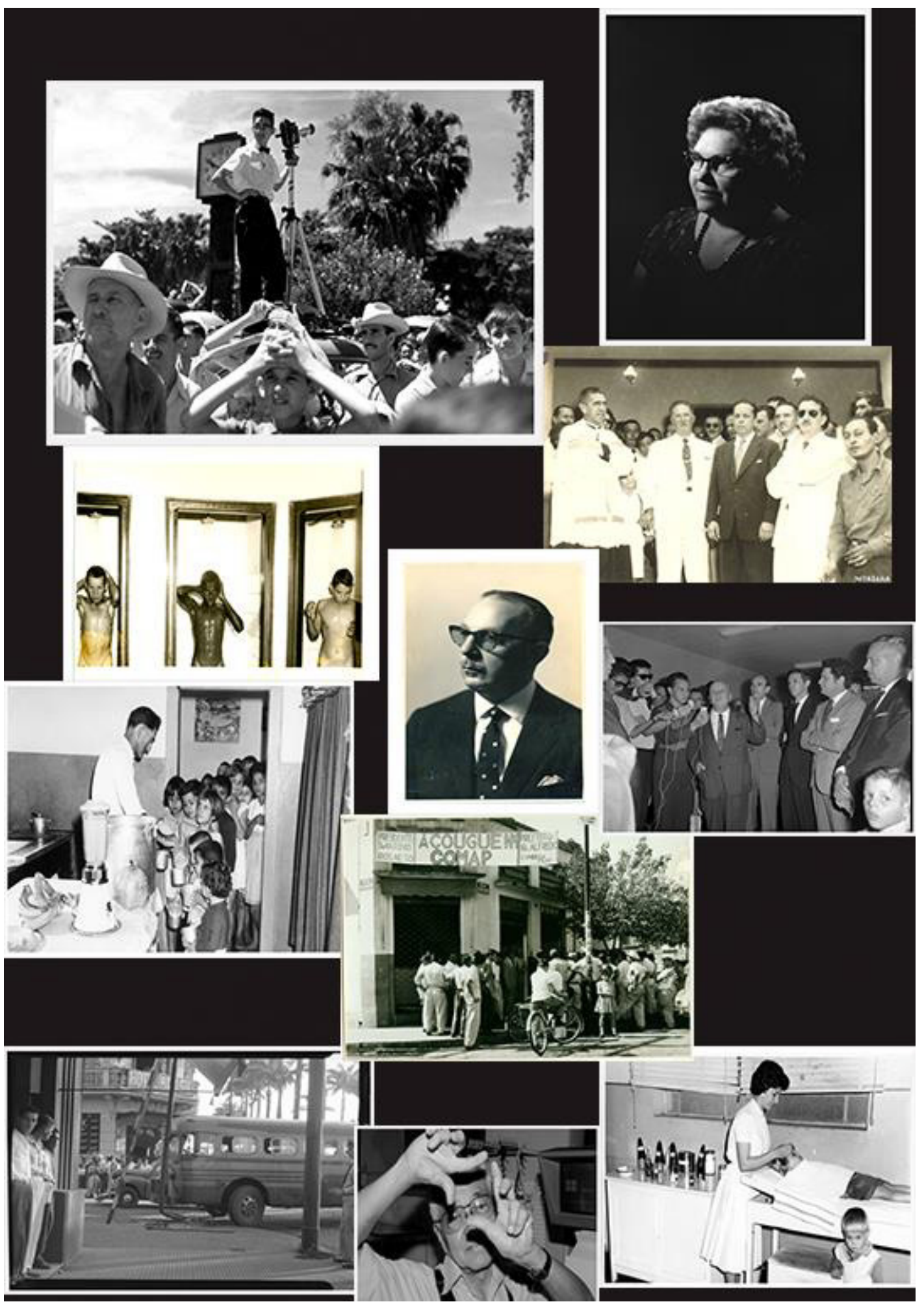

Figura 5 - Painel III, Rosto. Autor: Rafael F. A. Bezzon. Fonte: Arquivo Miyasaka e Arquivo Público e Histórico de Ribeirão Preto. 


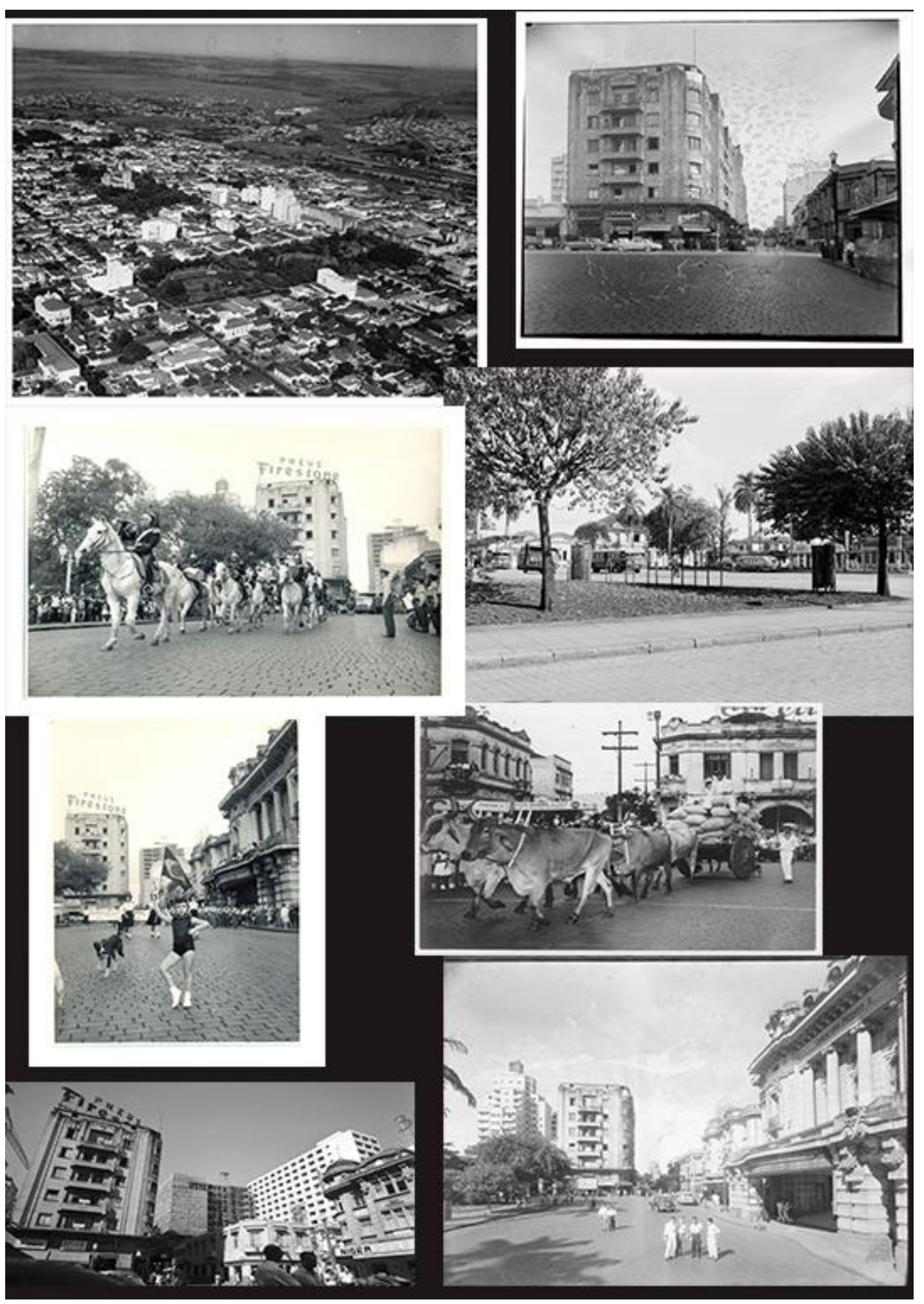

Figura 6 - Painel IV, Centro. Autor: Rafael F. A. Bezzon. Fonte: Arquivo Miyasaka e Arquivo Público e Histórico de Ribeirão Preto. 
Não é novidade que a fotografia, devido à sua materialidade, auxilia o pesquisador durante a experiência de pesquisa no estabelecimento de relações com os interlocutores. Como nos aponta Marcus Banks, “[...] Uma das forças das metodologias visuais em particular está na natureza inevitavelmente aberta da investigação. Resistindo a interpretações únicas, imagens podem fazer emergir todo um leque de caminhos alternativos de questionamento. [...]” (Banks 2009: 82). O antropólogo inglês lembra que as fotografias encontradas durante a pesquisa de campo são objetos estabelecidos em um contexto material. Esses artefatos imagéticos foram produzidos em uma determinada conjuntura, estão emaranhados com as biografias e trajetórias das pessoas que com ele constroem relações.

O pesquisador, de acordo com Banks (2009), deve conhecer os objetos e fotografias com os quais vai trabalhar e se relacionar durante a pesquisa, nas palavras de Banks (2009: 82), “[...] Usar arquivos fotográficos para despertar memória ou provocar comentários de informantes no decorrer de uma entrevista, por exemplo, envolve um reconhecimento de pelo menos três inserções sociais ou quadros." Ou seja, essas imagens e seus suportes tiveram diversos momentos de vida durante sua existência. E através das relações estabelecidas com os seus diferentes observadores é possível acessar os detalhes invisíveis que as envolvem, e as histórias a elas entrelaçadas.

Tudo se passa como se o observador quando em relação com as fotos às animasse assim como elas animam quem as observa, permitindo a evocação de lembranças, memórias e narrativas, através do contato com determinada imagem. Por outro lado, as imagens também apresentam uma qualidade interessante, podem ser entendidas como “[...] um 'arquivo de memórias humanas' ou uma 'sobrevivência' sociocultural, capaz de armazenar, veicular e fomentar não somente 'tempos', mas também 'pensamentos' a eles ancorados. [...]” (Bruno 2008: 2).

As fotos, e as imagens em geral, atuam como uma espécie de detonadores de memórias, ou seja, como se através do contato com a imagem irrompessem lampejos de informações que as complementam. Assim, esses "encontros fotográficos” possibilitam o avivamento da memória através de narrativas memorialísticas. Como toda pesquisa essa também se constitui das escolhas teórico-metodológicas realizadas, sendo assim 
são esses encontros e suas imagens que são mobilizados para a constituição das reflexões aqui apresentadas. ${ }^{9}$

Durante a realização da pesquisa no e com o Arquivo Miyasaka, as fotografias, as pessoas, e o arquivo agiram como interlocutores polissêmicos. São como fios, linhas soltas que se cruzam e se trançam, se relacionam e produzem relações, fabricando um nó ao entorno da imagem. É esse nó que conforma algumas fotografias tratadas nesse texto, faz emergir os invisíveis que rodeiam as imagens, as lembranças e histórias que se relacionam e se tornam latentes a partir do contato do observador com as fotografias. Por outro lado, esses encontros fotográficos permitem aos pesquisadores se afetarem pelas imagens e através delas, construir linhas de leitura, formas de se relacionar, e novas formas de expressar a experiência de pesquisa.

\section{REFERÊNCIAS}

AGIER, Michel. Encontros etnográficos: interação, contexto, comparação. 1. Edição, São Paulo: Editora Unesp; Alagoas: Edufal, 2015.

BANKS, Marcus. 2009. Dados visuais para pesquisa qualitativa. 1.Edição, Porto Alegre: Artmed.

BANKS, Marcus; VOKES, Richard. Introduction: Anthropology, Photography and the Archive. In. History and Anthropology, vol.21, n.4, p.337-349, 2010.

BARTHES, Roland. A câmara clara: nota sobre a fotografia. 3. Edição, Rio de Janeiro: Nova Fronteira, 2011.

BRUNO, Fabiana. 2008. Antropologia e Poética: Fotobiografia ou Imagens da Memória no Tempo da Velhice. In: $26^{a}$ Reunião Brasileira de Antropologia, Porto Seguro, Bahia.

CUNHA, Olívia Maria Gomes da. Do ponto de vista de quem? Diálogos, olhares e etnografias dos/nos arquivos. Estudos Históricos, Rio de Janeiro, 36:7-32, 2005.

DELEUZE, Gilles; PARNET, Claire. 1998. Diálogos. 1. Edição. São Paulo: Editora Escuta.

DIDI-HUBERMAN, Georges. Quando as imagens tocam o real. Pós: Belo Horizonte v.2, n.4: 204-219, 2012.

\footnotetext{
${ }^{9}$ É importante salientar que a proposta aqui apresentada é uma forma de se pesquisa e trabalhar com imagens, há outras que seguem outros caminhos teórico-metodológicos, e que trazem novos rendimentos para as imagens.
} 
EDWARDS, Elizabeth. Antropologia e Fotografia. Cadernos de Antropologia e Imagem, Rio de Janeiro, v.2, p.11-28, 1996.

---------. Photography and the Performance of History. Visual History, n.27, p.15-29, 2001.

---------. Uncertain Knowledge: Photography and the Turn-of-the-Century Anthropological Document. In Documenting the world: films, photography, and the scientific record. 1. Edição, Chicago; Londres: The University Chicago Press, 2016.

FAVRET-SAADA, Jeanne. Ser afetado. Cadernos de Campo, São Paulo, 13:155-161, 2005 .

KOSSOY, Boris. Realidades e Ficções na Trama Fotográfica. 4. Edição, São Paulo: Ateliê Editorial, 2009.

RANCIÈRE, Jacques. Figuras da História. 1. Edição, São Paulo: Editora Unesp, 2018.

SAMAIN, Etienne. “As Mnemosyne(s)" de Aby Warburg: Entre Antropologia, Imagens e Arte. Revista Poiésis, n 17: 29-51.

As peles da fotografia: fenômeno, memória/arquivo, desejo. Visualidades, v.10, n.1: 151-164, 2012.

STRATHERN, Marilyn. O efeito etnográfico. p. 345-405 in O efeito etnográfico e outros ensaios. São Paulo: Cosac Naify, 2014.

WAGNER, Roy. A invenção da cultura. 1. Edição, São Paulo: Cosac-Naify, 2012.

Recebido: $31 / 01 / 2020$

Aprovado: 15/07/2020 